\title{
Polypyrrole Fibre Electrodes for Drug Sensing ${ }^{\dagger}$
}

\author{
Sutthima Sriprasertsuk, John R. Varcoe and Carol Crean * \\ Department of Chemistry, University of Surrey, Guildford GU2 7XH, UK; s.sriprasertsuk@surrey.ac.uk (S.S.); \\ J.Varcoe@surrey.ac.uk (J.R.V.) \\ * Correspondence: c.crean@surrey.ac.uk \\ + Presented at the International Conference on the Challenges, Opportunities, \\ Innovations and Applications in Electronic Textiles (E-Textiles 2019), London, UK, 12 November 2019.
}

Published: 18 January 2020

\begin{abstract}
Polypyrrole (PPy) fibre electrodes and their ability to sense paracetamol (as a model drug) in addition to interferents such as ascorbic acid and dopamine were studied. PPy was electrodeposited onto carbon fibre (CF) through electropolymerisation using cyclic voltammetry in the presence of two different counter anions: potassium nitrate $\left(\mathrm{KNO}_{3}\right)$ and sodium dodecyl sulfate (SDS). PPy with SDS as dopant could sense paracetamol with an oxidation peak at $0.55 \mathrm{~V}$ vs. $\mathrm{Ag} / \mathrm{AgCl}$. The limit of detection of this fibre sensor was found to be $1 \mu \mathrm{M}$ with a linear range of $1-100 \mu \mathrm{M}$ of paracetamol $\left(\mathrm{R}^{2}=0.985\right)$.
\end{abstract}

Keywords: polypyrrole; fibre electrode; cyclic voltammetry; drug sensing; wearable sensors

\section{Introduction}

Polypyrrole (PPy) is a biocompatible conductive polymer, with good electrical conductivity, electrochemical switching, and flexibility, which makes it an ideal flexible electrode material $[1,2]$. Counterions are employed to balance the charge of the PPy film. Anions are incorporated during oxidation to stabilise the radical cation intermediate and are then displaced during reduction, whereas cations merge with the reduced PPy film to balance the negative charge [3,4]. Figure 1 illustrates the structure of PPy in its oxidised form (p-doped), with a counterion used to balance the charge. The aim of this work was to fabricate a fibre electrode with a PPy coating to improve the ability of the fibre electrode to sense paracetamol (as model drug) in addition to interferents such as ascorbic acid and dopamine.

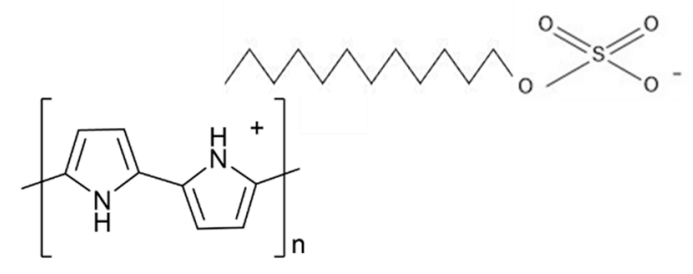

(a)

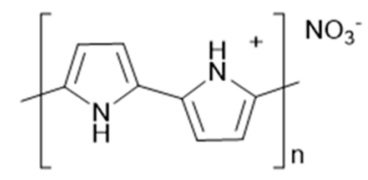

(b)

Figure 1. Schematic of polypyrrole (PPy) in the oxidised form with different counterions (a) dodecylsulfate; (b) nitrate.

\section{Materials and Methods}

\subsection{Reagents}

Analytical grade pyrrole $(98 \%)$, potassium nitrate $\left(\mathrm{KNO}_{3}\right)$, sodium dodecyl sulfate (SDS), paracetamol, dopamine hydrochloride, and L-ascorbic acid were purchased from Sigma-Aldrich 
(Gillingham, UK). Phosphate buffered saline (PBS) tablets were purchased from Fisher Scientific (Loughborough, UK). Carbon fibre was purchased from Alfa Aesar (Heysham, UK).

\subsection{Apparatus}

All cyclic voltammetry (CV) was performed using an eDAQ EA161 potentiostat with an eDAQ e-corder 401 supported by EChem V2.1.16 software. A Basi ${ }^{\circledR} \mathrm{Ag} / \mathrm{AgCl}$ in $3.0 \mathrm{M} \mathrm{NaCl}$ was used as a reference electrode and a platinum mesh was used as a counter electrode. Raman spectroscopy was performed using a Renishaw inVia confocal Raman microscope with a $785 \mathrm{~nm}$ laser. Scanning electron microscopy (SEM) images were obtained using a JEOL USA JSM-7100 F field emission electron microscope.

\subsection{Procedure}

PPy was electrodeposited onto carbon fibre (CF) through electropolymerisation using CV in the presence of two different counter anions: $\mathrm{KNO}_{3}$ and SDS. Deposition occurred over a potential range of -0.2 to $+1.0 \mathrm{~V}$ (vs. Ag/AgCl) at a scan rate of $50 \mathrm{mV} \mathrm{s}^{-1}$. The concentration of pyrrole was varied (from 0.02 to $0.2 \mathrm{M}$ ) together with the number of cycles (from 5 to 15 cycles) to optimize the PPy sensing layer.

The performance of the sensor with respect to paracetamol, interferents such as ascorbic acid, and dopamine (commonly found in blood) was tested [5]. The three-electrode system was used for analysis by $\mathrm{CV}$ at a potential range of -0.6 to $+0.9 \mathrm{~V}$ vs. $\mathrm{Ag} / \mathrm{AgCl}$ at a scan rate of $50 \mathrm{mV} \mathrm{s}^{-1}$ in $0-500 \mu \mathrm{M}$ of analyte solution.

\section{Results and Discussion}

\subsection{Characterisation}

Figure 2 shows the Raman spectrum of an uncoated carbon fibre, which illustrates peaks at 1577 and $1377 \mathrm{~cm}^{-1}$ corresponding to the $G$ and $D$ bands of carbon, respectively [6]. The Raman spectrum of a PPy.SDS coated CF confirms the deposition of PPy film onto the fibre electrode surface. The peak at $1572 \mathrm{~cm}^{-1}$ corresponds to $\mathrm{C}=\mathrm{C}$ stretching that is associated with the existence of polarons. The spectrum also displays the skeletal band at $1477 \mathrm{~cm}^{-1}$ and an antisymmetrical C-N stretching at $1384 \mathrm{~cm}^{-1}$. The peaks at $928 \mathrm{~cm}^{-1}$ and $1062 \mathrm{~cm}^{-1}$ relate to the bipolaron structure and those at $962 \mathrm{~cm}^{-1}$ and $1043 \mathrm{~cm}^{-1}$ to the polaron structure of PPy.

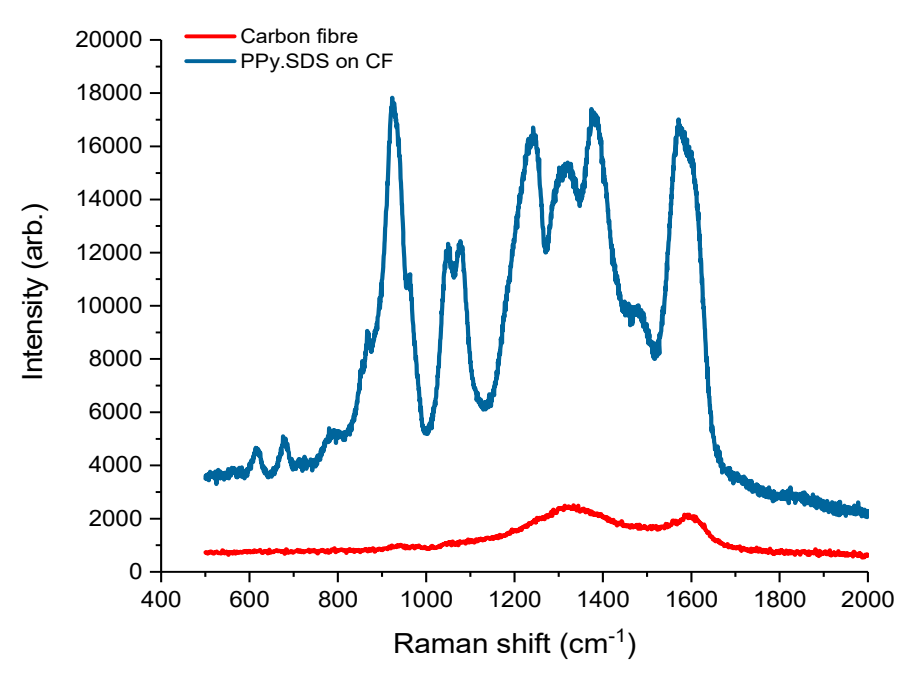

Figure 2. Raman spectrum of uncoated carbon fibre (red line) and PPy.SDS coated carbon fibre (blue line). 
Figure 3 displays the SEM images of CF both uncoated and coated with PPy. Uncoated CF have a smooth surface, whereas a rougher surface of the PPy.SDS film on the CF is noted in Figure $3 \mathrm{~b}$. The deposition of PPy with nitrate as counterion resulted in an unstable film on the CF surface (image not shown).
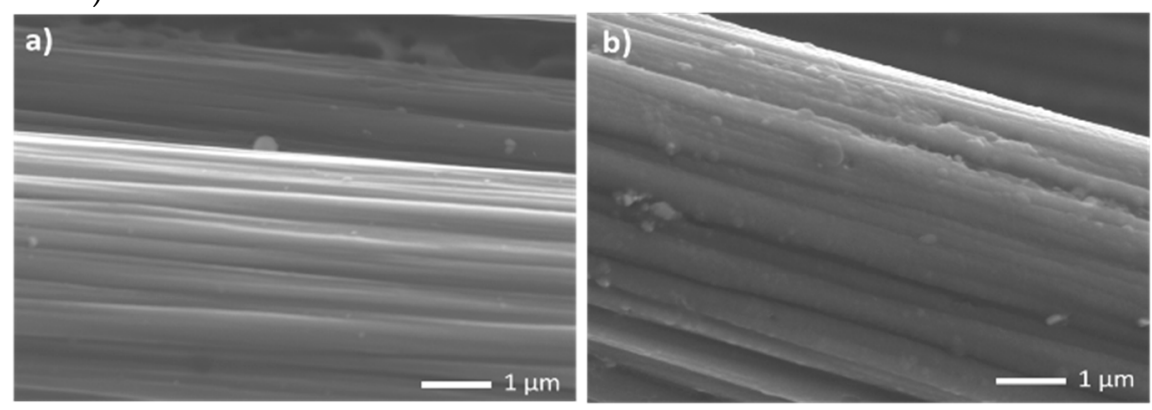

Figure 3. Scanning electron microscope images of (a) uncoated carbon fibre; (b) PPy.SDS coated carbon fibre.

\subsection{Surface Area of the Fibre Electrode}

Cyclic voltammetry post-polymerization (Figure 4a) show oxidation peak potentials at -0.75 and $0.10 \mathrm{~V}$ (vs. $\mathrm{Ag} / \mathrm{AgCl}$ ) for the PPy.SDS and $\mathrm{PPy}_{\mathrm{KNNO}}$ films on $\mathrm{CF}$, respectively. The surface area of the sensing fibre was calculated using the Randles-Sevcik equation; cyclic voltammetry was performed in $10 \mathrm{mM} \mathrm{K}{ }_{3} \mathrm{Fe}(\mathrm{CN})_{6}$ and $0.1 \mathrm{M} \mathrm{KCl}$ as supporting electrolyte at different scan rates. Table 1 shows how the PPy.SDS film on CF gave a five-fold increase in electrochemical surface area, whereas coating with PPy. $\mathrm{KNO}_{3}$ resulted in a four-fold increase. Figure $4 \mathrm{~b}$ displays the CVs of uncoated and PPy coated CF in potassium ferricyanide solution.

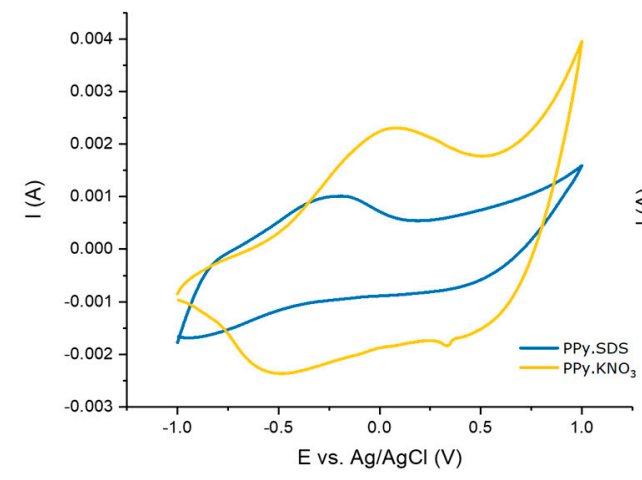

(a)

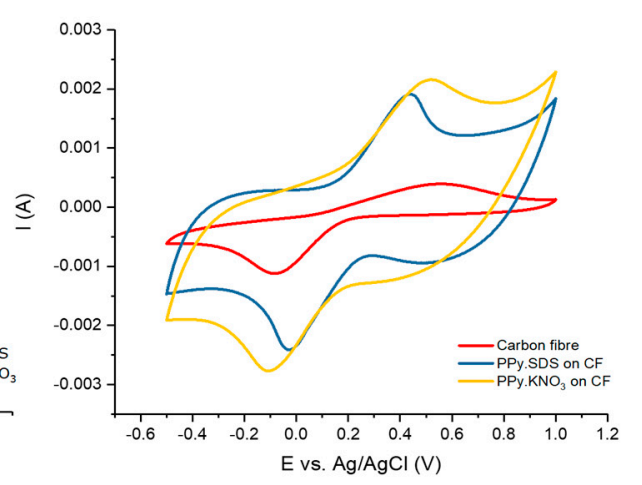

(b)

Figure 4. (a) Post-polymerisation cyclic voltammetry of PPy.SDS and $\mathrm{PPy} . \mathrm{KNO}_{3}$ on carbon fibre; (b) Cyclic voltammograms obtained for the fibre electrodes in $10 \mathrm{mM} \mathrm{K} 3 \mathrm{Fe}(\mathrm{CN})_{6}$ and $0.1 \mathrm{M} \mathrm{KCl}$ solution at a scan rate of $50 \mathrm{mVs}^{-1}$.

Table 1. Surface area of uncoated carbon fibre and PPy-coated carbon fibre.

\begin{tabular}{cccc}
\hline \multirow{2}{*}{ Scan Rate $\left(\mathrm{mV} \mathrm{s}^{-1}\right)$} & \multicolumn{3}{c}{ Surface Area $\left(\mathrm{cm}^{2}\right)$} \\
\cline { 2 - 4 } & CF & PPy.SDS on CF & PPy.KNO on $_{\text {CF }}$ \\
\hline 50 & 0.18 & 0.92 & 0.71 \\
\hline
\end{tabular}

\subsection{Drug Sensing}

The oxidation of paracetamol of the CF electrode was not evidenced in cyclic voltammetry. Figure 5a shows the sensing ability of PPy.SDS on CF in various concentrations of paracetamol at a scan rate of $50 \mathrm{mVs}^{-1}$. The oxidation peak of paracetamol was found at $0.55 \mathrm{~V}$ (vs. $\mathrm{Ag} / \mathrm{AgCl}$ ). Furthermore, the PPy.SDS on CF could sense dopamine and ascorbic acid at oxidation peaks of 0.35 and $0.25 \mathrm{~V}$ (vs. $\mathrm{Ag} / \mathrm{AgCl}$ ), respectively (results not shown). PPy. $\mathrm{KNO}_{3}$ was not a stable electrode, 
as evidenced by changing signals during analysis. A calibration curve for paracetamol sensing with PPy.SDS on CF is shown in Figure $5 \mathrm{~b}$ using the peak current value plotted against concentration. The limit of detection of this fibre sensor was found to be $1 \mu \mathrm{M}$ with a linear range of $1-100 \mu \mathrm{M}$ of paracetamol $\left(R^{2}=0.985\right)$.

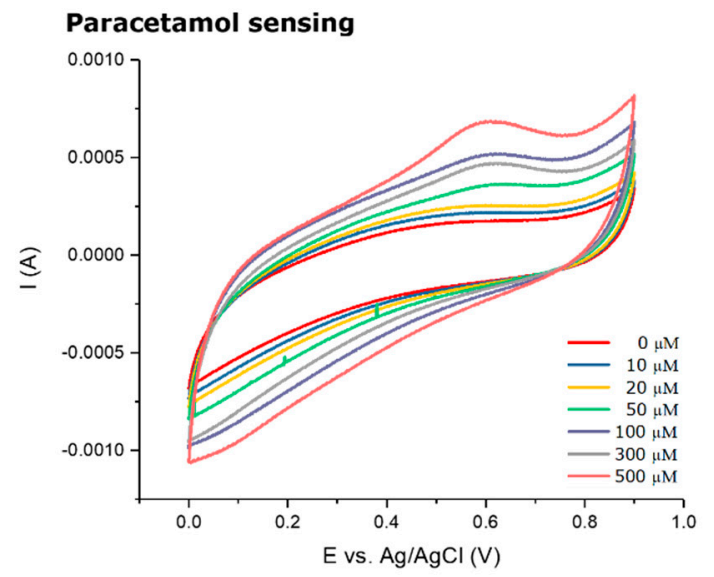

(a)

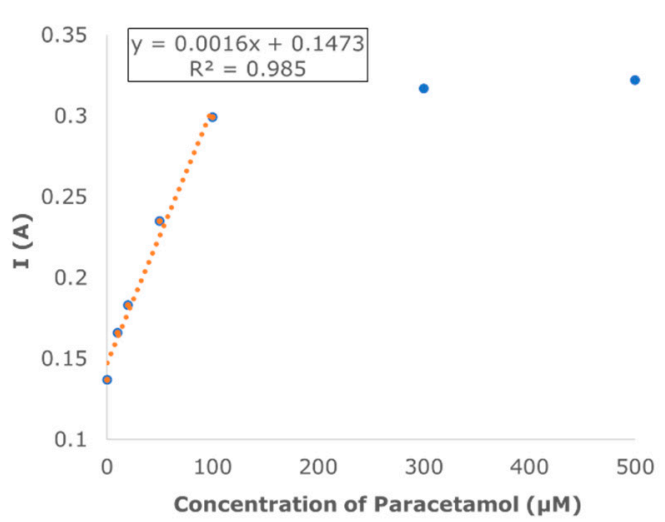

(b)

Figure 5. (a) PPy.SDS on CF sensing various concentration of paracetamol in $0.1 \mathrm{M}$ PBS solution at a scan rate of $50 \mathrm{mVs}^{-1}$; (b) calibration curve for PPy.SDS on CF with a concentration range of 0-500 $\mu \mathrm{M}$ paracetamol in $0.1 \mathrm{M}$ PBS solution.

\section{Conclusions}

The electropolymerisation of PPy onto a carbon fibre electrode improves the sensor's ability to detect paracetamol, ascorbic acid, and dopamine. The PPy.SDS films provided insight into how a large counterion positively affects the sensing capabilities of the film, as the use of SDS shows a good response and improved the stability of the film compared to $\mathrm{PPy} . \mathrm{KNO}_{3}$ (which was not a stable sensor). Further work is underway to sense a broader range of drug molecules and to improve the fibre sensor response with further surface modification.

Acknowledgments: The authors thank the Royal Thai Government Scholarship for providing funding for this work as well as the EPSRC grant, EP/M022749/1.

Conflicts of Interest: The authors declare no conflict of interest and the funders had no role in the design of the study; in the collection, analyses, or interpretation of data; in the writing of the manuscript, or in the decision to publish the results.

\section{References}

1. Kaur, G.; Adhikari, R.; Cass, P.; Bown, M.; Gunatillake, P. Electrically conductive polymers and composites for biomedical applications. RSC Adv. 2015, 5, 37553-37567.

2. Tang, T.; Yin, N.; Chen, S.Y.; Ou Yang, Y.; Chen, S.Y. Preparation and Characterization Flexible Conductive PPy/BC Nanocomposite Membrane. Adv. Mater. Res. 2012, 476-478, 755-758.

3. Li, S.; Guo, X. Influence of Doping Anions on the Ion Exchange Behavior of Polypyrrole. J. Appl. Polym. Sci. 2009, 119, 2307-2314.

4. Bagheri, H.; Ayazi, Z.; Naderi, M. Conductive polymer-based microextraction methods: A review. Anal. Chim. Acta 2013, 767, 1-13. 
5. Ghanbari, K.; Bonyadi, S. An electrochemical sensor based on reduced graphene oxide decorated with polypyrrole nanofibres and zinc oxide-copper oxide $p-n$ junction heterostructures for the simultaneous voltammetric determination of ascorbic acid, dopamine, paracetamol and tryptopha. New J. Chem. 2018, 42, 8512-8523.

6. Garcia-Torres, J.; Crean, C. Multilayered flexible fibers with high performance for wearable supercapacitor applications. Adv. Sustain. Syst. 2017, 1700143, doi:10.1002/adsu.201700143.

(C) 2020 by the authors. Licensee MDPI, Basel, Switzerland. This article is an open access article distributed under the terms and conditions of the Creative Commons Attribution (CC BY) license (http://creativecommons.org/licenses/by/4.0/). 